\title{
Epinephrine Facilitates Neurogenic Vasoconstriction in Humans
}

\author{
John S. Floras, Philip E. Aylward, Ronald G. Victor, Allyn L. Mark, and Francois M. Abboud \\ Cardiovascular Division of the Department of Internal Medicine and The Cardiovascular Center, \\ University of Iowa College of Medicine, University of Iowa Hospitals and Clinics, Iowa City, \\ Iowa 52242; and Veterans Administration Medical Center, Iowa City, Iowa 52240
}

\section{Abstract}

Numerous studies have suggested that epinephrine may facilitate neural release of $\mathrm{NE}$. There have been no studies in humans that demonstrate the functional significance of this action. To determine whether epinephrine facilitates neurogenic vasoconstriction in humans, we contrasted forearm vasoconstrictor responses to a reflex stimulus (lower body negative pressure [LBNP]) and to intraarterial NE before, during, and $30 \mathrm{~min}$ after infusion of epinephrine $(50 \mathrm{ng} / \mathrm{min}$ ) or isoproterenol (10 or $25 \mathrm{ng} / \mathrm{min})$ into a brachial artery. These doses had no systemic effects. We reasoned that if prejunctional stimulation of beta receptors by epinephrine and isoproterenol had functional significance, the vasoconstrictor response to LBNP would be potentiated in comparison to the response to $\mathrm{NE}$ (postjunctional mechanism).

Studies were done on 23 normal male volunteers. Forearm blood flow was measured with a strain gauge plethysmograph and intraarterial pressure was recorded. The ratio of vasoconstrictor responses to $\mathrm{LBNP} / \mathrm{NE}$ was used as an index of neural release of the neurotransmitter NE. This ratio increased during infusions of both epinephrine and isoproterenol. $30 \mathrm{~min}$ after epinephrine the vasoconstrictor response to LBNP ( $n$ $=15)$ was augmented from $+9.9 \pm 2.2(\mathrm{SE})$ resistance units (RU) before epinephrine to $+16.4 \pm 3.2 \mathrm{RU}(P<0.05)$; whereas the response to $\mathrm{NE}(n=8)$ tended to decrease from $+8.8 \pm 3.1$ RU before to $+4.2 \pm 1.2 \mathrm{RU}$ after epinephrine $(P>0.05)$. In contrast, $30 \mathrm{~min}$ after isoproterenol the vasoconstrictor responses to LBNP and NE were the same as before isoproterenol. The augmented ratio of responses to LBNP/NE after epinephrine and not after isoproterenol supports the concept that epinephrine, but not isoproterenol, is taken up by the adrenergic terminal, is released subsequently during reflex stimulation, and augments the release of the neurotransmitter NE.

These experiments provide the first hemodynamic evidence in humans that epinephrine and isoproterenol facilitate neurogenic vasoconstriction. The sustained effect of epinephrine in contrast to isoproterenol suggests that the late facilitation

Parts of this work were presented at the 69th Annual Meeting, Federation of American Societies for Experimental Biology, April 25, 1985, at the 42nd Annual Meeting, American Federation for Clinical Research, May 4, 1985, and at the 39th Annual Meeting, Council for High Blood Pressure Research, September 20, 1985.

Address correspondence to Dr. Abboud, Professor of Medicine and Physiology, Dept. of Internal Medicine, University of Iowa College of Medicine, Iowa City, IA 52242.

Received for publication 20 December 1985 and in revised form 29 September 1987.

The Journal of Clinical Investigation, Inc.

Volume 81, April 1988, 1265-1274 by epinephrine is related to its neural uptake and subsequent release.

\section{Introduction}

Epinephrine facilitates noradrenergic transmission in isolated tissues and intact animals by stimulating prejunctional beta adrenoceptors. These receptors appear to be beta- 2 in most species, including man (1-8). Because the affinity of epinephrine for beta-2 receptors is more than 200 -fold greater than that of NE, one of the physiological roles subserved by epinephrine may be to modulate NE release $(2,9,10)$.

Epinephrine can be taken up into postganglionic sympathetic nerves and released as a co-transmitter with NE for $24 \mathrm{~h}$ after its uptake $(8,10-14)$. When released, epinephrine augments the simultaneous discharge of endogenous NE. Thus, the facilitated release of NE may occur after exogenous administration of epinephrine, even when its plasma concentrations have returned to basal levels (12). Several authors $(6,9,12)$ have suggested that endogenous epinephrine could increase $\mathrm{NE}$ release in man by this mechanism both during and after episodes of sympathoadrenal stimulation. If so, this effect would provide a potential neural role for epinephrine in both essential hypertension and pheochromocytoma.

There is some evidence in man to support the concept that prejunctional beta receptor stimulation by epinephrine facilitates noradrenergic transmission. However, measurements of plasma NE concentrations during intravenous administration of beta receptor agonists have been equivocal, and the studies had limitations (15-17). When the agonists are given intravenously, heart rate and blood pressure change and neurogenic reflex pathways are activated and alter the release and clearance of NE independently of prejunctional influences. Further, the higher doses of epinephrine used could inhibit NE release by stimulating prejunctional alpha-2-adrenoceptors $(9,12)$.

Tachycardia persists after infusion of epinephrine, although its plasma concentration and systemic effects return to basal levels within minutes $(6,15)$. This sustained response does not follow administration of isoproterenol, which is not taken up by sympathetic nerves $(15,18)$, and can be prevented if subjects are pretreated with desmethylimipramine to reduce the neuronal uptake of epinephrine. These studies support the concept that epinephrine can modulate NE release both directly, and as a co-transmitter, although postjunctional responses to the neurotransmitter NE were not examined, and central and other indirect effects cannot be excluded because of the intravenous administration of the beta agonists.

In our studies, we explored these concepts as they relate to neurogenic vasoconstriction in humans.

Our first aim was to determine whether epinephrine augments neurogenic vasoconstriction. To answer this question we contrasted the forearm vascular responses to neurogenic 
PERIOD 1 (PRE-EPI)

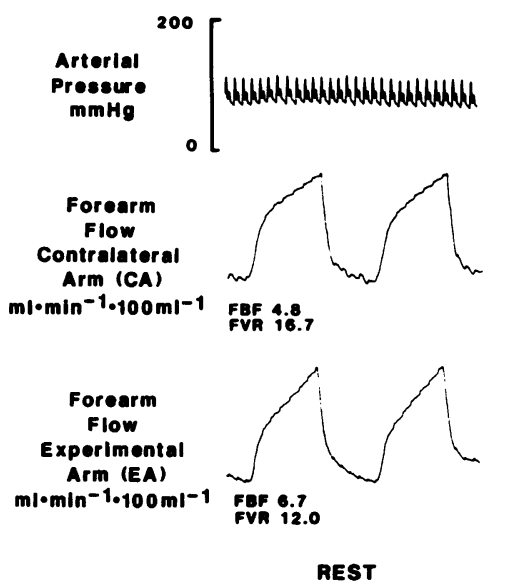

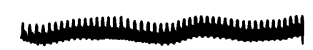
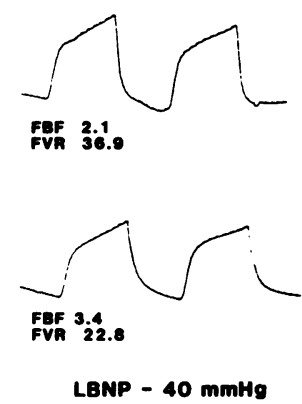

PERIOD 3 (POST-EPI)

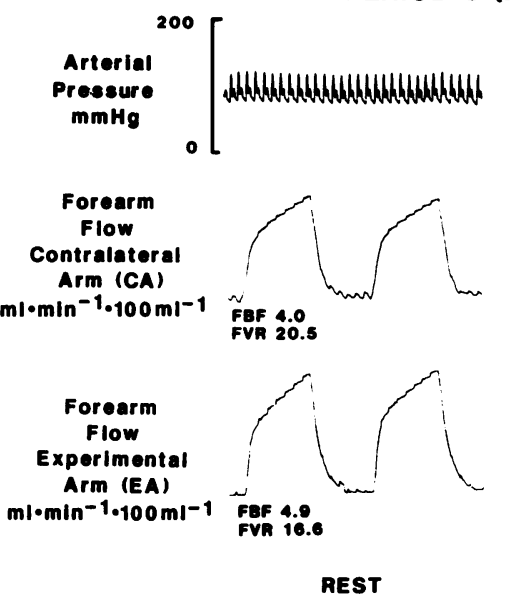

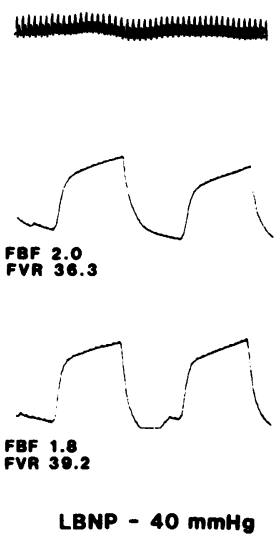

Figure 1. Blood pressure $(\mathrm{mmHg})$ and $\mathrm{FBF}\left(\mathrm{ml} \cdot \mathrm{min}^{-1} \cdot 100 \mathrm{ml}^{-1}\right.$ forearm volume) in the cannulated, or experimental arm (EA), and in the opposite, or contralateral arm (CA). Panels, left to right: resting values obtained before epinephrine; $\mathrm{LBNP}$ at $-40 \mathrm{mmHg}$, before epinephrine; resting values $30 \mathrm{~min}$ after intraarterial epinephrine; $\mathrm{LBNP}$ at $-40 \mathrm{mmHg}$, after epinephrine.

vasoconstriction (lower body negative pressure [LBNP]) ${ }^{1}$ and to intraarterial NE before and during an intraarterial infusion of epinephrine. Our hypothesis was that epinephrine would potentiate the response to the neurogenic stimulus, mediated through the release of endogenous NE, but not augment the vasoconstrictor response to $\mathrm{NE}$, which is mediated by postjunctional mechanisms.

Our second aim was to investigate the possibility of a sustained effect of epinephrine in modulating the vasoconstrictor response to neurogenic stimulation. Between 40 and $70 \%$ of arterial epinephrine is removed in one circulation through the forearm $(19,20)$. Our hypothesis was that if epinephrine is taken up and subsequently released from nerve endings as a co-transmitter, we might find a selective augmentation of reflex vasoconstriction after epinephrine, but not after isoproterenol, which is not taken up by the nerve endings.

The distinctive features of this study relative to previous studies in humans are: $(a)$ the demonstration of the effect on neurogenic vasoconstriction, which is critical in assessing the functional hemodynamic significance of the phenomenon; and $(b)$ the use of local (intraarterial), rather than systemic, administration of epinephrine and isoproterenol, which has two important advantages. First, it avoids systemic effects that confound the interpretation of the results and allows us to localize the site of action to the neuroeffector region. Second, the use of the opposite "contralateral arm" allows us to assess the stability and reproducibility of responses to the neurogenic stimulus.

\section{Methods}

\section{Subject selection}

23 male volunteers, aged 19-28 yr (mean 22.4) were studied. A medical history and physical examination were performed to exclude any illness, hypertension, or use of medication. The research protocol was

1. Abbreviations used in this paper: ANOVA, analysis of variance; EPI, epinephrine hydrochloride; FBF, forearm blood flow; FVR, forearm vascular resistance; ISO, isoproterenol hydrochloride; LBNP, lower body negative pressure; RU, resistance unit. approved by the Human Subjects Review Committee of the University of Iowa. Informed written consent was obtained after the rationale, nature, and potential risks of this research were explained.

\section{Procedures}

Subjects were supine during the study. After local anesthesia with $1 \%$ lidocaine, a No. $5 \mathrm{~F}$ polyethylene arterial catheter was inserted percutaneously into the brachial artery of one arm (experimental arm). A central venous catheter was introduced into an antecubital vein of the opposite arm (contralateral arm) and advanced to an intrathoracic position. Arterial and central venous pressures and respiratory excursions were measured continuously by Statham P23 ID pressure transducers and recorded simultaneously with the heart rate, electrocardiogram, and forearm blood flow (FBF) (Gould 2800S recorder).

FBF was measured by venous occlusion plethysmography (21). The arm was elevated and supported so that the proximal part of the forearm was $\sim 10 \mathrm{~cm}$ above the anterior chest wall. Circulation to the hand was interrupted by inflating a cuff wrapped around the wrist to $180 \mathrm{mmHg}$. A second cuff was wrapped around the arm above the antecubital crease and intermittently inflated to $40 \mathrm{mmHg}$. The sequential inflation and deflation of this cuff were timed to give four measurements of FBF each minute. Whitney strain gauges were applied $\sim 5 \mathrm{~cm}$ distal to the antecubital crease. FBF was measured simultaneously in both arms. Forearm vascular resistance ([FVR] expressed as resistance units [RU]), was calculated by dividing mean arterial pressure (diastolic pressure plus one-third of the pulse pressure [ $\mathrm{mmHg}$ ]) by the average of four to six measures of FBF (milliliters per minute per $100 \mathrm{ml}$ of forearm volume) (Fig. 1).

\section{Neurogenic vasoconstriction}

LBNP was used to cause reflex vasoconstriction (Fig. 1). An LBNP chamber (22) was placed over the patient's body below the iliac crest and sealed. Negative pressure was applied incrementally at $-10,-20$, and $-40 \mathrm{mmHg}$ for $90-120 \mathrm{~s}$ each. FBF was measured in both arms during the last $60 \mathrm{~s}$ of each level of LBNP, and immediately after LBNP.

\section{Intraarterial infusions of epinephrine and isoproterenol}

Infusions were made into the experimental arm only. Epinephrine hydrochloride (EPI) was diluted in 5\% dextrose and administered at a dose of $50 \mathrm{ng} / \mathrm{min}$ by constant infusion into the brachial artery at a rate of $0.83 \mathrm{ml} / \mathrm{min}$. Isoproterenol hydrochloride (ISO) in $5 \%$ dextrose was infused intraarterially at doses of 10 or $25 \mathrm{ng} / \mathrm{min}$, also at a rate of 0.83 $\mathrm{ml} / \mathrm{min}$. 
These doses were selected after pilot studies confirmed that they did not affect systemic hemodynamics or FBF in the contralateral arm, but were sufficient to produce local vascular responses.

\section{Intraarterial infusion of $N E$}

We considered the possibility that epinephrine or isoproterenol might alter the vascular responsiveness to the released transmitter NE during neurogenic vasoconstriction rather than the amount released. Thus, to take into consideration possible changes in postjunctional responses to the released NE or the effects of changes in baseline resistance or other temporal factors, we contrasted the increase in FVR during LBNP at $-40 \mathrm{mmHg}$, to the vasoconstrictor response to intraarterial NE. We compared the ratio of vasoconstrictor responses with LBNP vs. vasoconstrictor responses to NE before, during, and after the infusion of epinephrine or isoproterenol. An increase in this ratio during or after as compared with before the infusion of epinephrine or isoproterenol was used as an index of facilitated release of the endogenous transmitter NE during LBNP.

NE bitartrate was diluted in 5\% dextrose and infused intraarterially using a Harvard continuous pump at rates of $0.38 \mathrm{ml} / \mathrm{min}$ for $10 \mathrm{~min}$ and $0.76 \mathrm{ml} / \mathrm{min}$ for $5 \mathrm{~min}$ to achieve doses of 9 and $18 \mathrm{ng} / \mathrm{min}$, respectively. Maximal vasoconstrictor responses, which were obtained during the last $60-90 \mathrm{~s}$ of infusion at $18 \mathrm{ng} / \mathrm{min}$, are reported. These doses had no systemic effects and no effects on the opposite forearm.

\section{Protocols}

27 experiments were done on 23 subjects. Four of the subjects participated in two of the three series.

\section{SERIES 1: EFFECT OF EPINEPHRINE ON FOREARM}

\section{VASOCONSTRICTOR RESPONSES}

The forearm vasoconstrictor responses to LBNP were compared during three consecutive periods in 15 subjects. In eight of these subjects, responses to intraarterial NE were contrasted with the responses to LBNP during the same three periods.

Control period (period 1). 5\% dextrose in water was continually infused into the brachial artery at $0.83 \mathrm{ml} / \mathrm{min}$. Responses to LBNP and to intraarterial NE were measured.

Epinephrine period (period 2). After a 10-min rest period, epinephrine, $50 \mathrm{ng} / \mathrm{min}$, was infused intraarterially instead of dextrose and after $10 \mathrm{~min}$, responses to LBNP and to intraarterial NE were measured while the infusion of epinephrine continued. The epinephrine infusion lasted $\mathbf{4 0} \mathrm{min}$.

Postepinephrine period (period 3). The epinephrine infusion was stopped and dextrose resumed. $30 \mathrm{~min}$ later, responses to LBNP and to NE were obtained.

\section{SERIES 2: EFFECT OF ISOPROTERENOL ON FOREARM VASOCONSTRICTOR RESPONSES}

In six subjects, the forearm vasoconstrictor responses to LBNP and intraarterial NE were compared during the infusion of dextrose (period 1); during a 40-min intraarterial infusion of isoproterenol $(10 \mathrm{ng} / \mathrm{min}$ or $25 \mathrm{ng} / \mathrm{min}$; period 2); and $30 \mathrm{~min}$ after the end of isoproterenol (period 3). The lower concentrations of isoproterenol were infused to avoid any systemic effect in those subjects in whom a minimal systemic effect was detected at the higher dose.

During control periods of series 1 and 2,5\% dextrose in water was infused into the brachial artery at $0.83 \mathrm{ml} / \mathrm{min}$ as vehicle in place of epinephrine or isoproterenol. In five of the subjects, FBF was $4.7 \pm 0.6$ (mean \pm SE) before and $4.4 \pm 0.6 \mathrm{ml} / \mathrm{min}$ per $100 \mathrm{ml}$ forearm volume during the dextrose infusion. Thus, as noted previously in our laboratory, the volumes of infusate used in this study do not influence FBF (23).

\section{SERIES 3: EFFECT OF EXOGENOUS NE ON FOREARM} VASOCONSTRICTOR RESPONSES

These experiments were done in six subjects because of the possibility that in series 1 and 2 the responses to intraarterial NE might have been altered during period 3 by the prior infusions of NE in periods 1 and 2 rather than by epinephrine or isoproterenol. The aim, therefore, was to determine whether a sustained intraarterial infusion of NE would alter the vasoconstrictor response to a subsequent infusion of NE. These experiments provided in addition a time control with respect to the vasomotor responses to $\mathrm{NE}$ in the cannulated arm in the absence of epinephrine and isoproterenol.

FBF was measured at rest, then NE was infused into the brachial artery for $10 \mathrm{~min}$ at a dose of $18 \mathrm{ng} / \mathrm{min}$ and for $5 \mathrm{~min}$ at $36 \mathrm{ng} / \mathrm{min}$. The maximal responses, which were obtained during the last $60-90 \mathrm{~s}$ of infusion at $36 \mathrm{ng} / \mathrm{min}$, were recorded. These responses coincide to period 1 in series 1 and 2 .

The NE infusion was continued at $36 \mathrm{ng} / \mathrm{min}$ for an additional 25 $\mathrm{min}$ after which dextrose was infused instead of $\mathrm{NE}$, and 30 min later the forearm vasoconstrictor response to intraarterial NE (superimposed on dextrose) was determined as in the control period. The latter responses to NE coincide to responses in period 3 of series 1 and 2 . The similarity of responses to $\mathrm{NE}$ at the beginning and end of the infusions reflects the stability of vasomotor responses to the neurotransmitter over time.

\section{Statistical design and analysis}

The purpose was to determine the effect of EPI and of ISO on responses to LBNP and NE in the experimental arm. This was done by comparing results during the control period (1) to results during period 2. Period 3 allowed us to determine whether the effect of EPI or ISO was sustained. This design allowed us to use the same experimental arm as its own control and spare the subjects another arterial cannula in the contralateral arm. The measurement of forearm resistance in the contralateral arm, however, allowed us to demonstrate that the stimulus of LBNP (which was repeated throughout the three periods) was constant, i.e., it caused reproducible results in the absence of epinephrine or isoproterenol. This was essential to ascribe the change in the effect of LBNP to epinephrine or isoproterenol rather than to a change in the magnitude of response to LBNP with time or a change in the degree of the stimulus. Although the amount of suction during LBNP was the same, other factors may have affected the reproducibility of the reflex response over the 2- or 3-h period of the experiment. The change in FVR in the contralateral arm in response to LBNP was constant in the three periods; thus we could ascribe any change in the response of the experimental arm in period 2 compared with period 1 to the infusion of epinephrine or isoproterenol during period 2. Similarly, a change in response in period 3 compared with period 1 could be ascribed to the after effect or sustained action of epinephrine or isoproterenol.

Thus, the key comparisons were not those between the two arms but rather those between the three periods in the same arm (i.e., "period $\times$ condition" interactions in each arm separately).

Because of the cannulation, baseline flow was high in the experimental arm, and the infusions of epinephrine and isoproterenol increased flow further during period 2 because they are potent vasodilators. To interpret a change in response to LBNP correctly, it was important to determine whether the change in baseline FVR with epinephrine or isoproterenol would change the reactivity of the experimental arm to the neurotransmitter NE. Thus, we could deduce whether epinephrine or isoproterenol altered the reflex response to LBNP from two observations: (i) knowing that the stimulus (LBNP) was constant during the three periods (from responses in the untreated contralateral arm); and (ii) determining the responsiveness of the forearm vessels to the intraarterial infusion of the neurotransmitter NE in each of the three periods (in the experimental arm). Since epinephrine and isoproterenol may facilitate the neural release of NE during LBNP we compared responses to LBNP to responses to intraarterial NE in the same experimental arm during each period. This allowed us to evaluate the magnitude and functional significance of the facilitated release of NE. This is the main purpose of the experiment.

Several analyses of variances (ANOVA) were done but a few are shown in the tables below for brevity of presentation. We first used a 
Table I. ANOVA for Resistance in Experimental Arm in Series 1 and 2

\begin{tabular}{lrrrr}
\hline \multicolumn{1}{c}{ Source } & DF & Sum of squares & F value & $P>$ F \\
\hline Period & 2 & 4437.83 & 44.82 & 0.0001 \\
Condition & 3 & 6462.73 & 43.52 & 0.0001 \\
Period $\times$ condition & 6 & 559.80 & 1.88 & 0.0873 \\
Subject & 13 & 15792.82 & 24.54 & 0.0001 \\
Error & 143 & 7078.94 & & \\
Total & 167 & 34332.13 & & \\
& & & & \\
& & & &
\end{tabular}

four-way ANOVA combining series 1 and 2 to assess the effects of the three periods (1, 2, and 3), two arms (experimental and contralateral), four conditions (rest, LBNP, NE 0 , and NE 18), and 14 subjects on the variance. These analyses (not shown) indicated a significant "period $X$ arm" interaction for both flow $(P<0.001)$ and resistance $(P$ $<0.001$ ), i.e., the effect of period in these responses differed in the two arms, necessitating arm-specific analyses.

Therefore separate analyses were completed for each arm. Note that the correlation matrix across the twelve times of measurement (three periods and four conditions for each period) were compound symmetric for both arms and for both flow and resistance. This indicates that the degrees of freedom utilized in the repeated measures ANOVA tables reported are appropriate.

ANOVA in the contralateral arm (not shown) indicated a signifcant "condition" effect and the lack of a significant period effect. Tukey's test was utilized to confirm which condition was different. The significant condition effect represented the influence of LBNP, since $\mathrm{NE}$ was never injected into the contralateral arm and the NE injected in the experimental arm had no systemic effect or influence on the contralateral arm. The absence of a significant period effect is as expected and confirms the stability of the effect of LBNP during the three periods. ANOVA of the experimental arm (Table I) shows a significant effect of period and condition in series 1 and 2 .

To determine which periods differed and which conditions differed we applied Tukey's tests (Table II). The responses to LBNP and to NE were significant and these effects differed in the three periods.

Since the differences between periods included responses to both LBNP and NE (18 ng/ml) during series 1 (EPI) and series 2 (ISO), we analyzed the effects of LBNP and of NE separately in each series.

In series 1 (EPI) LBNP caused greater responses in period 3; periods 2 and 1 were not different. Whether all 15 subjects or only the 8 who received NE were included in the analysis the effect of LBNP was greater in period 3 (Table III). NE on the other hand caused smaller responses in period $2(P<0.05)$; periods 1 and 3 were not different (analyses not shown).

In series 2 (ISO), responses to LBNP were not different in the three periods. Responses to NE were smaller in period 2; periods 1 and 3 were not different (analyses not shown).
It was important to determine whether the forearm vasoconstrictor response to LBNP relative to NE is augmented in period 2 and period 3 , compared with period 1 , in each series. The Kruskal-Wallis test was used to assess the effect of epinephrine and isoproterenol on the ratios of vasoconstrictor responses to LBNP vs. NE, which were not normally distributed.

Flow and resistance at rest during period 1 of each series were compared in the two arms using paired Student's $t$ test. This test was also used to compare FVR before and after NE in series 3.

Values in the text, figures, and tables are expressed as mean $\pm \mathrm{SE}$. Statistical significance was taken as $P<0.05$.

\section{Results}

\section{Series 1: effect of epinephrine on forearm vasoconstrictor responses}

\section{RESTING VALUES}

There were no or minimal changes in resting hemodynamics and in resting flow and vascular resistance in the contralateral arm during the three periods (Table IV). In the experimental forearm, intraarterial epinephrine caused an increase in resting flow, and a decrease in vascular resistance. This vasodilation disappeared $30 \mathrm{~min}$ after cessation of epinephrine in period 3 (Table IV).

\section{VASOCONSTRICTOR RESPONSES}

Contralateral arm. In the contralateral arm $(n=15)$, increases in FVR with LBNP, $-40 \mathrm{mmHg}$, did not differ before $(+16.7 \pm 2.6 \mathrm{RU})$, during $(+16.9 \pm 2.4 \mathrm{RU})$, and after (+14.0 $\pm 2.6 \mathrm{RU})$ epinephrine (Table IV; Fig. 3), indicating the reproducibility of the stimulus and responses in the absence of interventions over time.

Experimental arm. In the experimental arm $(n=15)$, the vasoconstrictor response to $\mathrm{LBNP},-40 \mathrm{mmHg}$, was similar before (+9.9 $\pm 2.2 \mathrm{RU})$ and during (+10.6 $\pm 2.2 \mathrm{RU})$ the epinephrine infusion despite the fall in initial FVR, from $17.6 \pm 1.9$ to $12.7 \pm 1.6 \mathrm{RU}$ during epinephrine $(P<0.01)$ (Table IV, Fig. 2). 30 min after epinephrine when resting resistance had returned to control values, the increase in FVR with LBNP, $-40 \mathrm{mmHg}(+16.4 \pm 3.2 \mathrm{RU})$, was significantly greater than the response before epinephrine $(+9.9 \pm 2.2 ; P<0.005)$ (Table IV; Fig. 2). Responses to -10 and $-20 \mathrm{mmHg}$ LBNP tended to be greater after epinephrine than before $(P, \mathrm{NS})$ (Fig. 2).

In 8 of these 15 subjects, the responses to intraarterial NE in the experimental arm decreased from $+8.8 \pm 3.1 \mathrm{RU}$ before to $+2.6 \pm 2.3 \mathrm{RU}(P<0.01)$ during epinephrine (Fig. 3). 30 min after epinephrine, the response to $\mathrm{NE}$ was restored in part $(+4.2 \pm 1.2 \mathrm{RU})$.

Table II. Tukey's Tests of the Effects of "Conditions" and of "Periods" on Resistance in Experimental Arm in Series 1 and 2

\begin{tabular}{|c|c|c|c|c|c|c|c|}
\hline \multirow[b]{2}{*}{ Grouping } & \multicolumn{3}{|c|}{ Condition effects* } & \multirow[b]{2}{*}{ Grouping } & \multicolumn{3}{|c|}{ Period effects ${ }^{\ddagger}$} \\
\hline & Mean & $n$ & Condition & & Mean & $n$ & Period \\
\hline A & 31.629 & 42 & LBNP & $\mathbf{A}$ & 26.818 & 56 & 3 \\
\hline B & 21.676 & 42 & $18 \mathrm{NE}$ & B & 23.246 & 56 & 1 \\
\hline C & 16.655 & 42 & $0 \mathrm{NE}$ & C & 14.577 & 56 & 2 \\
\hline C & 16.229 & 42 & Rest & & & & \\
\hline
\end{tabular}

\footnotetext{
* The resistances that were not different were the resting values before LBNP (rest) and before NE (zero NE); both LBNP and NE (18 ng) caused significant effects. ${ }^{\ddagger}$ The responses were greater in period 3 than in period 1 , and greater in period 1 than in period 2 . This indicates that epinephrine and/or isoproterenol altered the effect of LBNP and/or NE in period 2 and in period 3.
} 
Table III. Tukey's Test of the Effect of "Periods" on Change in FVR during LBNP in the Experimental Arm (Series 1)

\begin{tabular}{cccccccc}
\hline Grouping & Mean & $n$ & Period & Grouping & Mean & $n$ & Period \\
\hline A & 16.393 & 15 & 3 & A & 22.164 & 8 \\
B & 10.567 & 15 & 2 & B & 13.236 & 8 \\
B & 9.880 & 15 & 1 & B & 13.225 & 8 & 1 \\
\hline
\end{tabular}

The effect was analyzed in all the 15 subjects in Series 1 and also in 8 of these 15 subjects who received NE. The results were similar and indicate that the effect of LBNP was greater in Period 3 and similar in Periods 1 and 2.

The ratio of responses to LBNP vs. NE in those eight subjects who received NE increased more than threefold both during $(P<0.01)$ and after $(P<0.05)$ epinephrine in comparison with period 1 (Fig. 4).

\section{Series 2: effect of isoproterenol on forearm vasoconstrictor responses}

\section{RESTING VALUES}

There were no or minimal changes in resting hemodynamics and in flow and vascular resistance in the contralateral arm during the three periods of this series (Table V). In the experimental arm, intraarterial isoproterenol caused an increase in resting blood flow and a decrease in vascular resistance. This vasodilation disappeared $30 \mathrm{~min}$ after cessation of isoproterenol in period 3 (Table V).

\section{VASOCONSTRICTOR RESPONSES}

Contralateral arm. In the contralateral arm, increases in FVR with LBNP did not differ during the three periods (Table V; Fig. 5).

Experimental arm. In the experimental arm the response to LBNP during isoproterenol $(+8.0 \pm 3.6 \mathrm{RU})$ tended to be lower than preisoproterenol $(+17.6 \pm 6.4 \mathrm{RU})$, but the difference was not statistically significant (Table V; Fig. 5). In contrast, the vasoconstrictor response to NE was markedly reduced, from $+7.3 \pm 2.9 \mathrm{RU}$ before to $+0.3 \pm 1.0 \mathrm{RU}$ during isoproterenol $(P<0.05)$ (Fig. 5). Thus, the ratio of the response to LBNP vs. NE increased from 2.4 before to 26.3 during isoproterenol.
30 min after cessation of isoproterenol, the vasoconstrictor responses to LBNP and NE (period 3) were not different from values recorded before isoproterenol (period 1) (Table V; Fig. 5).

\section{Series 3: effect of prolonged infusion of $N E$ on forearm vasoconstrictor responses to $N E$}

Resting arterial pressure, central venous pressure, heart rate, and FVR in each arm were similar before and $30 \mathrm{~min}$ after the prolonged (40 $\mathrm{min}$ ) intraarterial infusion of $\mathrm{NE}(36 \mathrm{ng} / \mathrm{min})$.

The vasoconstrictor response to $\mathrm{NE}(36 \mathrm{ng} / \mathrm{min})$ was similar before $(+7.4 \pm 1.8 \mathrm{RU})$ and after $(+6.9 \pm 2.0 \mathrm{RU})$ cessation of the prolonged intraarterial infusion of NE.

\section{Discussion}

The purpose of our study was to evaluate in humans the functional significance of the reported facilitated release of NE by epinephrine. We examined reflex vasoconstrictor responses to LBNP in 21 normal subjects. We made three observations. First, the forearm vasoconstrictor response to LBNP was preserved during intraarterial infusions of epinephrine and isoproterenol, whereas the response to NE was significantly attenuated. Second, the vasoconstrictor response to LBNP was significantly increased $30 \mathrm{~min}$ after cessation of epinephrine infusion. Third, the response was not increased $30 \mathrm{~min}$ after cessation of isoproterenol. These observations provide the evidence in humans that epinephrine augments neurogenic vaso-

Table IV. Effect of Epinephrine on Responses to LBNP $(n=15)$

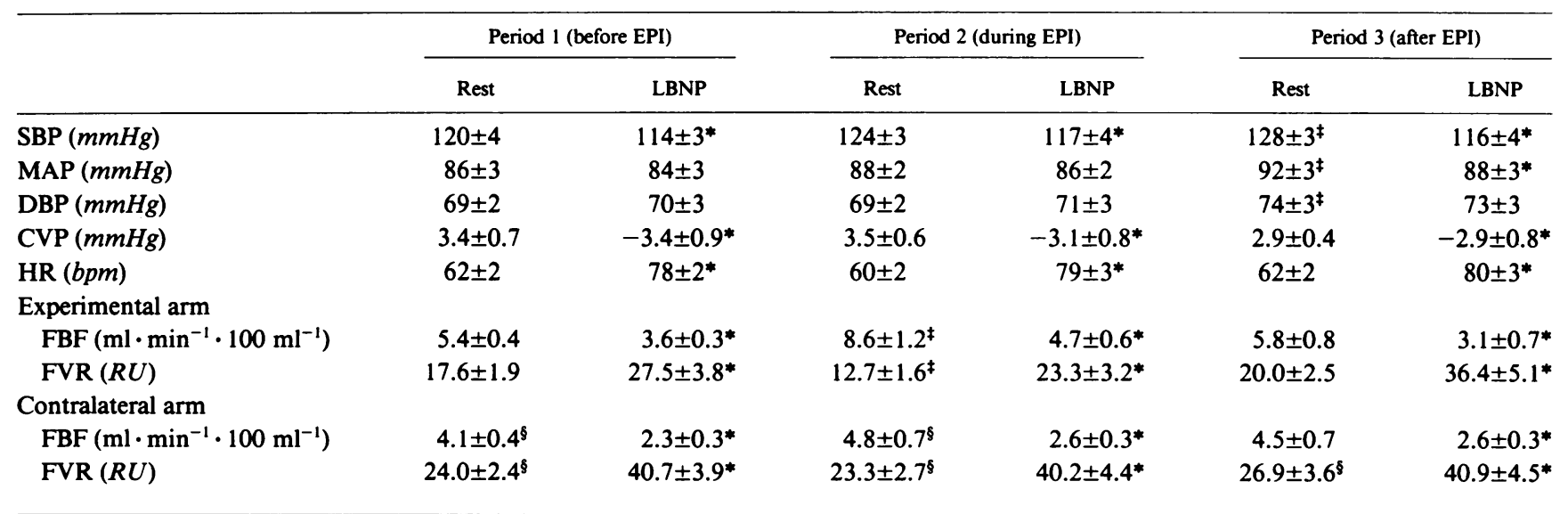

Series 1: Systemic and local hemodynamics at rest and during lower body negative pressure at $-40 \mathrm{mmHg}$ (LBNP) before (before EPI), during (EPI), and $30 \mathrm{~min}$ after (after EPI) an intraarterial infusion of epinephrine $(50 \mathrm{ng} / \mathrm{min})(\mathrm{EPI})(\mathrm{n}=15)$. SBP, Systolic blood pressure; MAP, mean arterial pressure; DBP, diastolic blood pressure; CVP, central venous pressure; and HR, heart rate. ${ }^{*} P<0.05$, LBNP compared with rest. ${ }^{\ddagger} P<0.05$, rest in periods 2 and 3 compared with period $1 .{ }^{\S} P<0.05$, resting value in contralateral arm compared with experimental arm. 


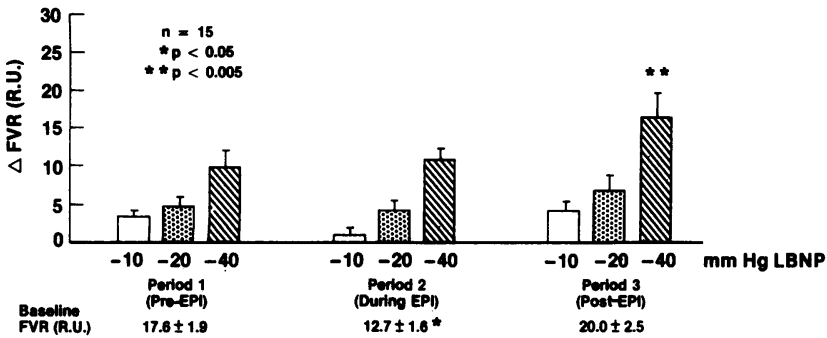

Figure 2. Series 1. Experimental arm. Forearm vasoconstrictor responses to $-10(\square),-20(\square)$, and $-40(\mathbb{B}) \mathrm{mmHg}$ of LBNP before (period 1), during (period 2), and $30 \mathrm{~min}$ after (period 3) the intraarterial infusion of epinephrine (EPI), $50 \mathrm{ng} / \mathrm{min}(n=15)\left({ }^{*} P<0.05\right.$, and ${ }^{* *} P<0.005$, compared with period 1 ).

constriction by an action on peripheral neuroeffector mechanisms. We postulate that this is because of facilitated release of the transmitter.

Although we did not study the effect of beta adrenoceptor antagonists on these responses, there is good evidence from experimental literature $(4,7,8,12)$ and human studies (17) that the facilitated NE release seen during epinephrine infusions can be prevented by beta adrenoceptor blockade, and after epinephrine by beta adrenoceptor and catecholamine uptake blockade.

Based on this conceptual framework, our observations are consistent with the hypothesis that beta adrenoceptor agonists facilitate the release of NE from sympathetic nerves, and the augmented neurogenic vasoconstriction seen $30 \mathrm{~min}$ after epinephrine suggests that the release of NE continued to be facilitated after local plasma concentrations of epinephrine returned to baseline.

We wish to focus our discussion on four points: $(i)$ The advantage of the chosen experimental design; (ii) The inter- pretation of the responses during infusions of epinephrine and isoproterenol; (iii) The interpretation of responses after cessation of epinephrine and isoproterenol; and (iv) The significance of the observations.

\section{(i) Experimental design}

Three elements are important. First, we compared the vasoconstrictor response to the neurogenic stimulus of NE release (LBNP) with the direct postjunctional response to intraarterial NE under the same experimental conditions. The neurogenic vasoconstrictor response to LBNP is influenced by both the amount of NE released from sympathetic nerves (facilitated by prejunctional beta receptor stimulation) and by the vascular responsiveness to neurally released NE. Both the neurally released and the exogenous NE stimulate postjunctional alpha-1 and alpha-2 vascular adrenoceptors equally $(24,25)$. The vascular responses to the neurally released NE could have been altered during the course of these experiments by postjunctional effects of isoproterenol and epinephrine and by changes in resting FVR. The magnitude of these effects was assessed by measuring responses to intraarterial NE. We could then use the ratio of forearm vasoconstrictor responses to LBNP/NE during each period of these studies as an index of the amount of NE released during LBNP.

Second, we measured FBF simultaneously in the contralateral arm for two reasons: $(a)$ to demonstrate that the infused catecholamines had no systemic indirect effects, and $(b)$ to confirm that LBNP caused a reproducible neurogenic vasoconstriction that remained stable over the course of the three periods in each series of experiments in the absence of infusion of EPI or ISO or NE. Differences between responses observed before, during, and after epinephrine or isoproterenol in the experimental arm could thus be ascribed to the local effects of these intraarterial agonists rather than to systemic or "time" effects.
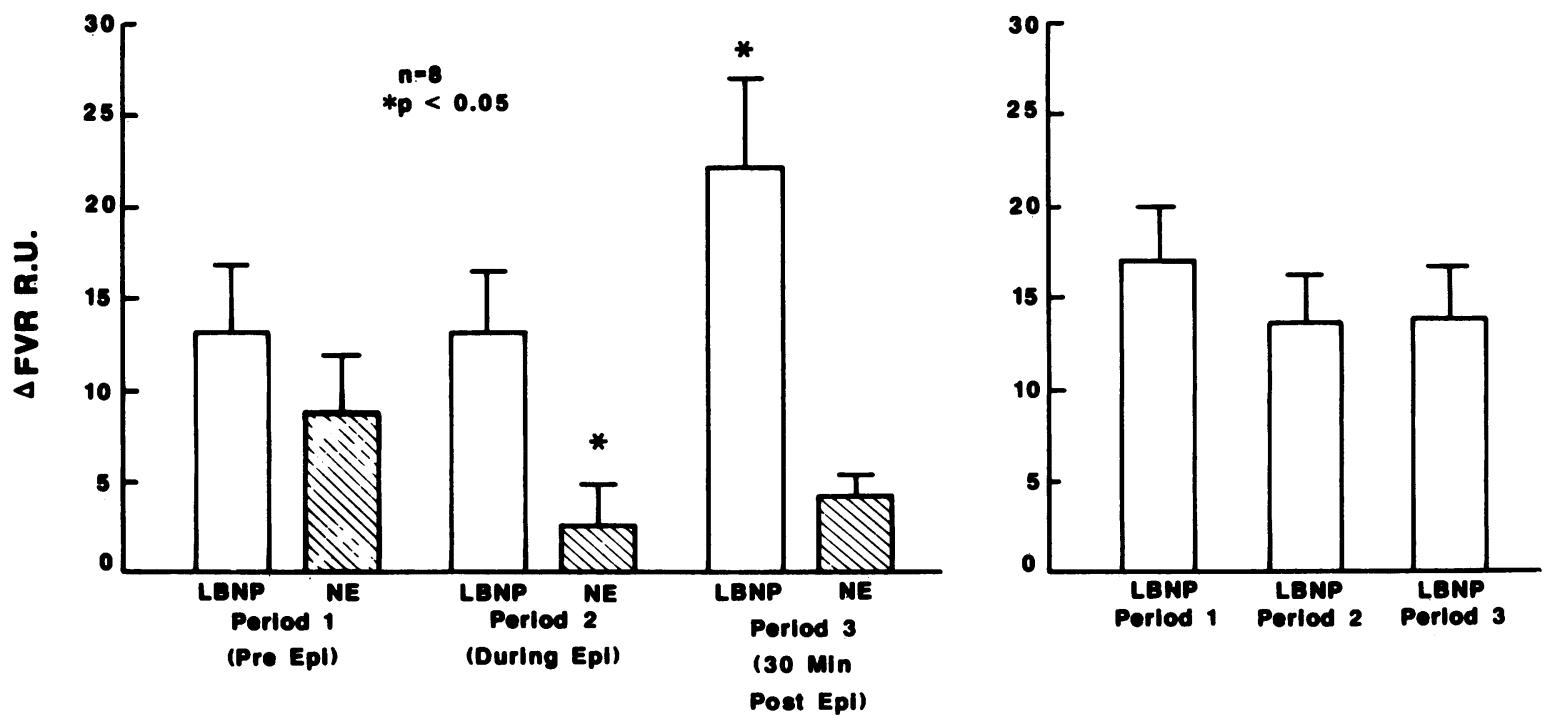

Figure 3. Series 1. Forearm vasoconstrictor responses to $-40 \mathrm{~mm}$ of $\mathrm{Hg}$ LBNP and to $18 \mathrm{ng} / \mathrm{min}$ of intraarterial NE, before (control period 1), during (period 2), and $30 \mathrm{~min}$ after (period 3) the intraarterial infusion of epinephrine (EPI), $50 \mathrm{ng} / \mathrm{min}$, into the experimental, or cannulated arm (left). Responses to LBNP only are in the contra- lateral arm (right) $\left({ }^{*} P<0.05\right.$, compared with period 1$)$. The ratio of LBNP vs. NE was significantly increased in periods 2 and 3, as compared with period 1 (see Fig. 4). The responses to LBNP in the contralateral arm did not differ during the three periods and indicate a reproducible effect of LBNP in the absence of intraarterial EPI. 


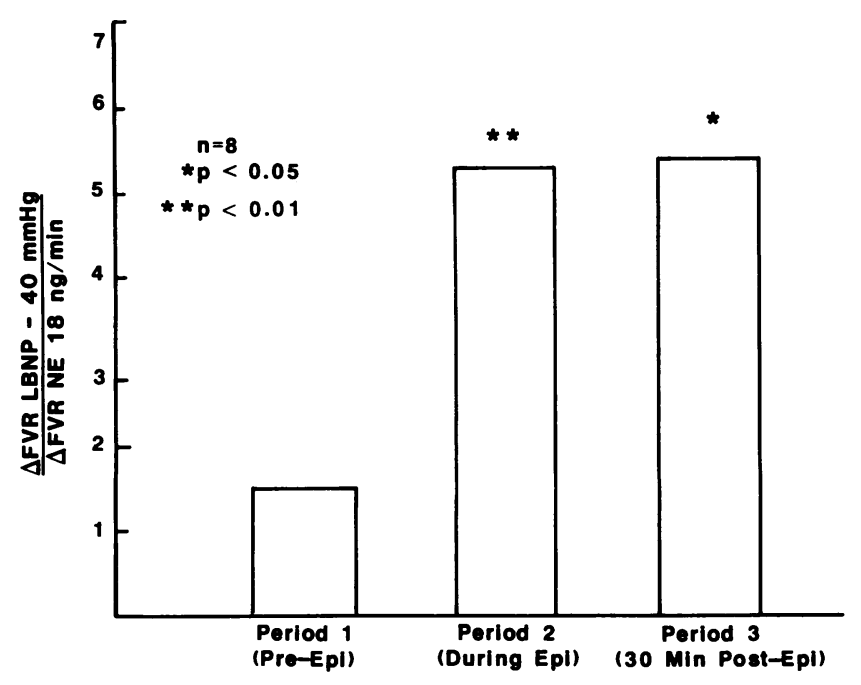

Figure 4. Series 1. Ratio of vasoconstrictor responses to $-40 \mathrm{~mm}$ of $\mathrm{Hg}$ LBNP and to $18 \mathrm{ng} / \mathrm{min}$ of intraarterial NE before (control period 1), during (period 2), and $30 \mathrm{~min}$ after (period 3) the intraarterial infusion of epinephrine (EPI), $50 \mathrm{ng} / \mathrm{min}$, into the experimental arm $\left({ }^{*} P<0.05,{ }^{* *} P<0.01\right.$, compared with period 1$)$. As anticipated from the responses shown in Fig. 3 the ratio LBNP/NE was greater in periods 2 and 3 than in period 1 , indicating facilitated release of NE with EPI infusions. These ratios were calculated from the eight subjects in series 1 in whom NE was infused.

Third, in contrast to previous workers who infused beta receptor agonists intravenously (15-17), we administered these catecholamines into the brachial artery at doses that restricted their effects to the experimental arm to localize their influence to peripheral neuroeffector sites and avoid potential effects on central and ganglionic sites or sensory afferents. The dose of epinephrine was calculated to raise its concentration within the experimental arm to levels seen during intense sympathoadrenal activation without the confounding systemic effects $(15,26)$. (ii) Interpretation of responses during epinephrine and isoproterenol

Changes in resting resistance. Both epinephrine and isoproterenol lowered the initial FVR in the experimental arm. We have previously found that the vasoconstrictor response to intraarterial NE falls when the initial FVR is reduced (27). We anticipated therefore that reducing FVR, these beta receptor agonists would attenuate the vasoconstrictor responses to both NE and LBNP, unless countered by increased NE release during LBNP. The vasoconstrictor response to LBNP $-40 \mathrm{mmHg}$ in the experimental arm was preserved, not attenuated, during the epinephrine infusion. This suggests that the reflex vasoconstrictor response was augmented. Furthermore, the response to NE was much less, and the response to LBNP/NE in the experimental arm was increased more than threefold during the epinephrine infusion, and more than tenfold during isoproterenol. These observations are consistent with the hypothesis that beta receptor agonists facilitate the release of NE from sympathetic nerves.

Decreased responses to $N E$. The reasons for the decreased responses to NE during epinephrine and isoproterenol may be complex. In human saphenous veins, postjunctional beta adrenoceptor-mediated vasodilation by isoproterenol will counter the vasoconstrictor response to NE (5). Although the net effect of epinephrine in these studies was vasodilation, epinephrine may occupy postjunctional alpha-2 receptor sites mediating vasoconstriction (28) and attenuate the vasoconstrictor response to a second agonist, i.e., NE, whether administered by infusion or released during LBNP.

Another factor to be considered is the redistribution of blood flow by epinephrine and isoproterenol away from resistance vessels which may be more reactive to NE (29). This redistribution might not affect the vasoconstrictor response to neurogenic vasoconstriction but could attenuate the response to infused NE. There may be a difference between epinephrine and isoproterenol in this respect because of their contrasting effect on alpha receptors and on skin blood flow (30). How-

Table V. Effect of Isoproterenol on Responses to LBNP $(n=6)$

\begin{tabular}{|c|c|c|c|c|c|c|}
\hline & \multicolumn{2}{|c|}{ Period 1 (before ISO) } & \multicolumn{2}{|c|}{ Period 2 (during ISO) } & \multicolumn{2}{|c|}{ Period 3 (after ISO) } \\
\hline MAP $(m m H g)$ & $81 \pm 1$ & $76 \pm 1^{*}$ & $85 \pm 2$ & $81 \pm 3$ & $88 \pm 2^{\ddagger}$ & $86 \pm 2$ \\
\hline $\mathrm{DBP}(\mathrm{mmHg})$ & $64 \pm 1$ & $62 \pm 2$ & $69 \pm 2$ & $67 \pm 3$ & $70 \pm 2^{\ddagger}$ & $72 \pm 2$ \\
\hline $\mathrm{CVP}(\mathrm{mmHg})$ & $4.2 \pm 0.8$ & $-2.9 \pm 1.1^{*}$ & $4.1 \pm 0.7$ & $-3.0 \pm 1.5^{*}$ & $4.8 \pm 0.7$ & $-2.1 \pm 1.4^{*}$ \\
\hline $\mathrm{FBF}\left(\mathrm{ml} \cdot \mathrm{min}^{-1} \cdot 100 \mathrm{ml}^{-1}\right)$ & $7.7 \pm 2.0$ & $3.7 \pm 1.0^{*}$ & $10.3 \pm 1.8^{\ddagger}$ & $5.7 \pm 1.2^{*}$ & $6.2 \pm 1.0$ & $3.0 \pm 0.6^{*}$ \\
\hline $\operatorname{FVR}(R U)$ & $15.9 \pm 4.4$ & $33.4 \pm 9.6^{*}$ & $10.2 \pm 2.6^{\ddagger}$ & $18.2 \pm 4.2^{*}$ & $16.0 \pm 2.7$ & $33.6 \pm 5.7^{*}$ \\
\hline \multicolumn{7}{|l|}{ Contralateral arm } \\
\hline $\mathrm{FBF}\left(\mathrm{ml} \cdot \mathrm{min}^{-1} \cdot 100 \mathrm{ml}^{-1}\right)$ & $5.1 \pm 1.9$ & $2.7 \pm 1.0^{*}$ & $5.3 \pm 2.0^{\S}$ & $3.1 \pm 1.2^{*}$ & $4.6 \pm 1.6$ & $2.9 \pm 1.0^{*}$ \\
\hline FVR $(R U)$ & $28.3 \pm 7.2$ & $47.5 \pm 19.4^{*}$ & $29.3 \pm 7.8^{8}$ & $46.3 \pm 11.0^{*}$ & $30.9 \pm 7.4^{\S}$ & $48.6 \pm 11.1^{*}$ \\
\hline
\end{tabular}

Series 2: Systemic and local hemodynamics at rest, during lower body negative pressure at $-40 \mathrm{mmHg}$ (LBNP): before (before ISO), during (during ISO), and $30 \mathrm{~min}$ after (after ISO) an intraarterial infusion of isoproterenol (10 or $25 \mathrm{ng} / \mathrm{min}$ ) (ISO) $(n=6)$. SBP, Systolic blood pressure; MAP, mean arterial pressure; DBP, diastolic blood pressure; CVP, central venous pressure; and HR, heart rate. ${ }^{*} P<0.05$, LBNP compared with rest. ${ }^{\ddagger} P<0.05$, rest in periods 2 and 3 compared with period $1 . \$ P<0.05$, resting value in contralateral arm compared with experimental arm. 

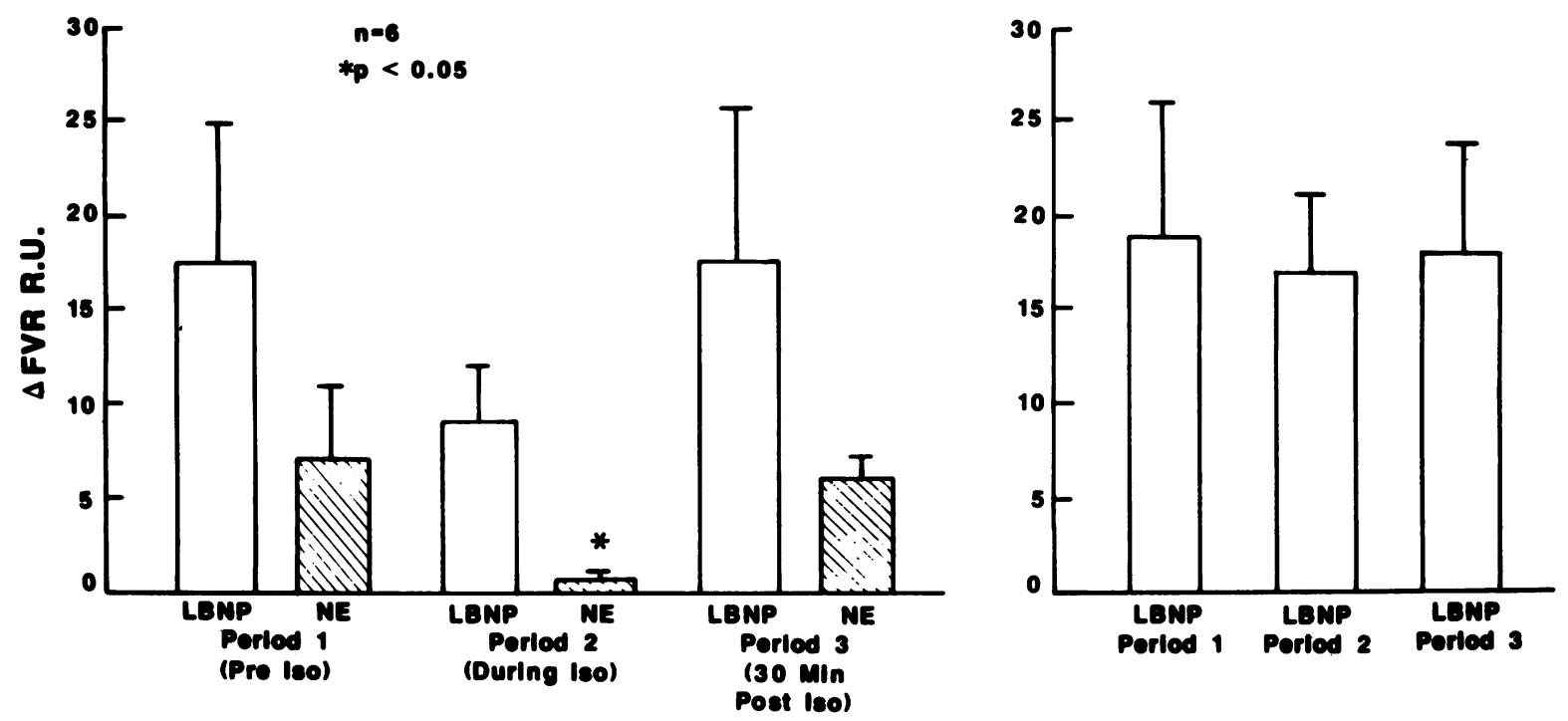

Figure 5. Series 2. Forearm vasoconstrictor responses to $-40 \mathrm{~mm}$ of $\mathrm{Hg} \mathrm{LBNP}$ and to $18 \mathrm{ng} / \mathrm{min}$ of intraarterial NE, before (control period 1), during (period 2), and $30 \mathrm{~min}$ after (period 3) the intraarterial infusion of isoproterenol (ISO), $10-25 \mathrm{ng} / \mathrm{min}$, into the experimental, or cannulated arm $(l e f t) .\left({ }^{*} P<0.05\right.$, compared with period 1). The decrease in response to NE in period 2 compared with period

1 without a significant change in the response to LBNP suggests facilitated release of NE during LBNP in period 2 only. Responses to LBNP alone are shown in the contralateral arm (right). The responses in the contralateral arm indicate a reproducible effect of LBNP during the three periods in the absence of intraarterial ISO.

ever, the response to NE was significantly reduced with both epinephrine and isoproterenol.

Finally, the increased FBF during the infusion of these beta receptor agonists would tend to reduce the concentration of the infused NE. However, the marked attenuation of the vasoconstrictor response to $18 \mathrm{ng} / \mathrm{min}$ NE during the epinephrine infusions was much greater than could be attributed to the $66 \%$ increase in FBF produced by epinephrine in the eight subjects in series 1 . The effect of the $66 \%$ increase in FBF during period 2 would be to dilute the concentration of infused $\mathrm{NE}$ proportionately to an amount equivalent to $11 \mathrm{ng} / \mathrm{min}$. Yet, the response to $18 \mathrm{ng} / \mathrm{min}$ during period $2(+2.6 \pm 2.3 \mathrm{RU})$ was not statistically significant and was certainly much less than expected with $11 \mathrm{ng} / \mathrm{min}$. In fact, $9 \mathrm{ng} / \mathrm{min}$ given during period 1 just before increasing the dose to $18 \mathrm{ng} / \mathrm{min}$ caused an increase in resistance of $+6.5 \pm 3.0 \mathrm{RU}(P<0.02)$ in these eight subjects. Thus, our conclusion is that dilution of NE in phase 2 does not explain the marked inhibition of responses to NE.

It is difficult to assess the relative contribution of these factors to the attenuated response to NE during epinephrine. However, those that exert a primarily postjunctional effect would be expected to reduce the response to NE and to LBNP to a comparable degree. We therefore interpret the absence of an attenuation of the response to LBNP when the response to $\mathrm{NE}$ is reduced as support for the concept of prejunctional facilitation of noradrenergic transmission by beta receptor stimulation.

\section{(iii) Interpretation of responses after cessation of infusion of epinephrine and isoproterenol}

The forearm vasoconstrictor response to LBNP, $-40 \mathrm{mmHg}$, was clearly increased $30 \mathrm{~min}$ after epinephrine. Since epinephrine has a half-life in plasma of only a few minutes $(12,31)$, changes in these responses seen $30 \mathrm{~min}$ after the infusion of epinephrine may be related to its uptake by nerve terminals rather than to its blood level. Moreover, the influence of changes in baseline resistance and postjunctional effects previously discussed, are minimized $30 \mathrm{~min}$ after cessation of epinephrine and isoproterenol. Since the ratio of forearm vasoconstrictor responses to LBNP/NE more than tripled after epinephrine, the augmented neurogenic vasoconstriction was probably caused by facilitation of NE release. $30 \mathrm{~min}$ after the infusion of isoproterenol, which is not taken up by sympathetic nerves, the vasoconstrictor response to the reflex stimulus was not augmented, nor was the ratio of vasoconstrictor responses to LBNP/NE. Although there may be other differences between these two catecholamines that may affect local responses, these findings are consistent with previous observations, using catecholamine uptake blockers in isolated tissues (8) and humans (6). We propose that the amplification of neurogenic vasoconstriction seen after cessation of epinephrine infusion and not after isoproterenol is due to the neural uptake and subsequent release of epinephrine, causing a facilitation of NE release as was seen in period 2.

A potential limitation to our interpretation of the ratio of responses to LBNP/NE as an index of neurotransmitter release is the possibility that the intraarterial administration of NE and epinephrine reduced the number or affinity of postjunctional alpha-2 receptors (thought to mediate humoral responses) without affecting postjunctional alpha-1 receptors (thought to mediate neural responses). If so, this selective down-regulation of alpha-2 receptors might have attenuated the vasoconstrictor response to exogenous NE infusions more than to the reflex stimuli. This, if true, would invalidate our use of exogenous NE as a test of postsynaptic integrity in the third period of series 1 . Although recent work has shown that postjunctional alpha-1 and alpha-2 receptors in human arm and hand vessels are activated equally by exogenous, and neurally released $\mathrm{NE}(24,25)$, we undertook the third series of investigations to exclude this possibility. If the attenuated re- 
sponse to NE during and post-EPI in series 1 were due to prior infusion of these alpha adrenoceptor agonists, a similar attenuation of the vasoconstrictor response to NE should have followed the prolonged infusion of NE in series 3 . This did not occur, indicating that the changes seen in the first series could not be explained by alterations in postjunctional alpha- 2 receptor responsiveness to infused agonists. These results also demonstrate the stability of the vasomotor responses to NE in the experimental arm after prolonged intraarterial infusion that did not include EPI and ISO.

The augmented response to LBNP might have been caused by a decrease in neuronal re-uptake of the released NE after epinephrine. This is unlikely, since one would expect that the response to the infused neurotransmitter would also be similarly augmented.

Since neurogenic vasoconstriction in periods 2 and 3 was preceded by infusions of NE, we considered the possibility that the augmented neurogenic vasoconstriction, particularly in period 3, could have been related to the uptake of infused NE and its subsequent release in higher local concentration independently of any effect of epinephrine. However, the forearm vasoconstrictor response to LBNP was augmented after epinephrine in those seven subjects in whom NE was not administered (+6.0 $\pm 1.4 \mathrm{RU}$ before vs. $+9.8 \pm 2.8 \mathrm{RU}$ after epinephrine, $P<0.05$ ). Furthermore, the response to LBNP was not augmented after NE and isoproterenol in period 3 of series 2 .

It is possible that prolonged infusions of epinephrine and isoproterenol may have down-regulated prejunctional beta receptors and epinephrine may have activated prejunctional alpha-2 adrenoceptors. These effects would inhibit, not enhance, NE release, and run contrary to our observations. It is obviously not possible to determine the precise prejunctional mechanism involved in these experiments, but the net effect is one of facilitated release, reasonably explained by a predominant beta receptor activation.

\section{(iv) Significance of these observations}

Our findings are compatible with the hypothesis $(13,32)$ that endogenous epinephrine may contribute to the initiation of essential hypertension by facilitating the release of NE from sympathetic nerves.

Current experimental evidence suggests that these effects are mediated through beta receptor stimulation, rather than through a nonspecific effect of epinephrine or isoproterenol, since beta adrenoceptor antagonists block similar neurogenic vascular responses in the rat hindlimb (14) and kidney (8), and in the saphenous veins of dog and man (5).

Several groups (33-35) have shown that infusions of epinephrine that do not increase plasma concentration can lead to a sustained elevation of blood pressure in rats. Brown $(6,15)$ has proposed that the dissociation between the short plasma half-life of epinephrine and the slow decay of the tachycardia after its infusion is due to a cyclical process of re-uptake and release of epinephrine from cardiac nerves.

We have focused on the vascular responses to beta receptor stimulation in these experiments. The normal forearm vascular response to epinephrine is vasodilation (30); we have demonstrated that epinephrine facilitates NE discharge and augments neurogenic vasoconstriction $30 \mathrm{~min}$ after it is infused. Thus, it appears that as a co-transmitter, the predominant effect of epinephrine in the forearm is prejunctionally mediated vasoconstriction, whereas as a humoral agent its pre- dominant effect is postjunctionally mediated vasodilation. We did not determine whether this augmentation can be elicited after increases in endogenous epinephrine, and we do not know whether it persists beyond the 30 -min period or decays after repetitive neurogenic stimulation. However, these observations suggest that epinephrine may exert a pro-hypertensive effect in humans minutes, possibly hours, after its direct cardiovascular effect has abated.

A neurogenic component to the higher blood pressure of patients with pheochromocytoma can be unmasked by the clonidine suppression test. $3 \mathrm{~h}$ after an oral dose of clonidine, blood pressure falls, presumably because of sympatho-inhibition, but plasma NE concentrations, predominantly of tumor origin, remain elevated (36). The dissociation between the fall in blood pressure and the high plasma NE suggests that neurally released NE may be more important than circulating NE in maintaining the hypertension of pheochromocytoma. Epinephrine, which circulates in concentrations well above the normal range, could act both directly, and as a co-transmitter on prejunctional receptors to increase noradrenergic release and augment neurogenic vasoconstriction in these patients, and contribute to higher resting pressures and paroxysmal hypertensive surges in this disorder.

Investigation of the role of the sympathetic nervous system in the initiation and maintenance of essential hypertension has focused on indirect measures of sympathetic activity such as plasma NE concentrations, or pressor responses to sympathetic stimulation. Few clear-cut differences between normal subjects and patients with high blood pressure have emerged from these studies (37). Recently Buhler et al. (38) described consistently elevated plasma epinephrine concentrations in some hypertensive subjects, not only at rest, but during submaximal exercise and a cold pressor test. Brodde et al. (39) found a strong positive correlation between lymphocyte beta receptor density and mean arterial pressure in a group of normal subjects and patients with borderline and established essential hypertension. A transient doubling of beta receptor binding sites in mononuclear cells and a greater heart rate response to a pulse of isoproterenol are evoked by a 30-60 min intravenous infusion of epinephrine or isoproterenol (40). Thus, as well as facilitating noradrenergic transmission, endogenous epinephrine may also acutely amplify beta adrenoceptor-mediated responses in the heart.

These findings, coupled with our present observations, lead us to suggest that some subjects prone to develop hypertension might manifest sustained increases in heart rate and cardiac output, and greater neurogenic vasoconstrictor responses to reflex stimuli than normal subjects after episodes of sympathoadrenal activation. When continued over months or years these sustained elevations of cardiac output and persistent augmentation of neurogenic vasoconstriction could serve to promote vascular hypertrophy and elevate the blood pressure of susceptible individuals.

\section{Acknowledgements}

The authors wish to thank Dr. Leon Burmeister for statistical consultation, Mr. James Kohler for his computing assistance, Mrs. Joan Kempf and Mrs. Chris Sinkey for their technical participation in these studies, and Nancy Stamp and Rita Yeggy for their expert typing.

Dr. Floras was a Canadian Heart Foundation Research Fellow, and Dr. Aylward was a National Heart Foundation of Australia Overseas 
Research Fellow. This work was supported by research grants HL24962 and HL14388 from the National Heart, Lung and Blood Institute, by research funds from the Veterans Administration, and by research grant RR59 from the Clinical Research Center Branch of National Institutes of Health.

\section{References}

1. Adler-Graschinsky, E., and S. Z. Langer. 1975. Possible role of a $\beta$-adrenoceptor in the regulation of noradrenaline release by nerve stimulation through a positive feedback mechanism. Br. J. Pharmacol. 53:43-50.

2. Stjarne, L., and J. Brundin. 1976. $\beta 2$-adrenoceptors facilitating noradrenaline secretion from human vasoconstrictor nerves. Acta Physiol. Scand. 97:88-93.

3. Majewski, H., M. W. McCullough, M. J. Rand, and D. F. Story. 1980. Adrenaline activation of prejunctional $\beta$-adrenoceptors in guinea-pig atria. Br. J. Pharmacol. 71:435-444.

4. Majewski, H. 1983. Modulation of norepinephrine release through activation of presynaptic $\beta$-adrenoreceptors. J. Auton. Pharmacol. 3:47-60.

5. Verbeuren, T. J., R. R. Lorenz, L. L. Aarhus, J. T. Shepherd, and P. M. Vanhoutte. 1983. Prejunctional beta-adrenoceptors in human and canine saphenous veins. J. Auton. Nerv. Syst. 8:261-271.

6. Brown, M. J., and C. T. Dollery. 1984. Adrenaline and hypertension. Clin. Exp. Hypertens. 6:539-549.

7. Schmitt, H. H. W. W., C. Schurr, L. Hedler, and H. Majewski. 1984. Local modulation of norepinephrine release in vivo: presynaptic $\beta 2$-adrenoceptors and endogenous epinephrine. J. Cardiovasc. Pharmacol. 6:641-649.

8. Quinn, P., K. R. Borkowski, and M. G. Collis. 1984. Epinephrine enhances neurogenic vasoconstriction in the rat perfused kidney. Hypertension. 7:47-52.

9. Stjarne, L., and J. Brundin. 1975. Dual adrenoceptor mediated control of noradrenaline secretion from human vasoconstrictor nerves: facilitation by $\beta$-receptors and inhibition by $\alpha$-receptors. Acta Physiol. Scand. 94:139-141.

10. Dahlof, C. 1981. Studies on $\beta$-adrenoceptor mediated facilitation of sympathetic neurotransmission. Acta Physiol. Scand. 500(Suppl.):1-147.

11. Rosell, S., J. Axelrod, and I. J. Kopin. 1964. Release of tritiated epinephrine following sympathetic nerve stimulation. Nature (Lond.). 201:301.

12. Majewski, H., M. J. Rand, and L.-H. Tung. 1981. Activation of prejunctional $\beta$-adrenoceptors in rat atria by adrenaline applied exogenously or released as a co-transmitter. Br. J. Pharmacol. 73:669-679.

13. Majewski, H., L. H. Tung, and M. J. Rand. 1982. Adrenaline activation of prejunctional $\beta$-adrenoceptors and hypertension. J. Cardiovasc. Pharmacol. 4:99-106.

14. Berecek, K. H., and M. J. Brody. 1982. Evidence for a neurotransmitter role for epinephrine derived from the adrenal medulla. Am. J. Physiol. 242(Heart Circ. Physiol. 11):H593-H601.

15. Brown, M. J., D. C. Brown, and M. B. Murphy. 1983. Hypokalaemia and $\beta 2$-receptor stimulation by circulating epinephrine. $N$. Engl. J. Med. 309:1414-1419.

16. Vincent, H. H., F. Boomsma, A. J. Man in't Veld, F. H. M. Derkx, G. H. Wenting, and M. A. D. H. Schalekamp. 1984. Effects of selective and nonselective $\beta$-agonists on plasma potassium and norepinephrine. J. Cardiovasc. Pharmacol. 6:107-114.

17. Nezu, M., Y. Miura, M. Adachi, M. Adachi, S. Kimura, S. Toriyabe, Y. Ishizuka, H. Ohashi, T. Sugawara, M. Takahashi, T. Noshiro, and K. Yoshinaga. 1985. The effects of epinephrine on norepinephrine release in essential hypertension. Hypertension. 7:187195.

18. Iversen, L. L. 1973. Catecholamine uptake processes. Br. Med. Bull. 29:130-135.
19. Halter, J. B., A. E. Pflug, and A. G. Tolas. 1980. Arterialvenous differences of plasma catecholamines in man. Metab. Clin. Exp. 29:9-12.

20. Hjemdahl, P., B. Eklund, and L. Kaijser. 1982. Catecholamine handling by the human forearm at rest and during isometric exercise and lower body negative pressure. Br. J. Pharmacol. 77:324P.

21. Greenfield, A. D. M., R. J. Whitney, and J. Mowbray. 1963. Methods for the investigation of peripheral blood flow. Br. Med. Bull. 19:101-109.

22. Zoller, R. P., A. L. Mark, F. M. Abboud, P. G. Schmid, and D. D. Heistad. 1972. The role of low pressure baroreceptors in reflex vasoconstrictor responses in man. J. Clin. Invest. 51:2967-2972.

23. Eckstein, J. W., M. G. Wendling, and F. M. Abboud. 1965. Forearm venous responses to stimulation of adrenergic receptors. $J$. Clin. Invest. 44:1151-1159.

24. Jie, K., P. van Brummelen, P. Vermey, P. B. M. W. M. Timmermans, and P. A. van Zwieten. 1984. Effects of exogenous adrenaline and noradrenaline on vascular postsynaptic $\alpha 1$ - and $\alpha 2$-adrenoceptors in man. J. Hypertension. 2(Suppl. 3):119-121.

25 . Stevens, M. J., and R. F. W. Moulds. 1985 . Neuronally released norepinephrine does not preferentially activate postjunctional $\alpha$-1-adrenoceptors in human blood vessels in vitro. Circ. Res. 57:399-405.

26. Vendsalu, A. 1960. Studies on adrenaline and noradrenaline in human plasma. Acta Physiol. Scand. 173:1-123.

27. Abboud, F. M., P. G. Schmid, and J. W. Eckstein. 1968. Vascular responses after alpha adrenergic receptor blockade. 1. Responses of capacitance and resistance vessels to norepinephrine in man. J. Clin. Invest. 47:1-9.

28. Bolli, P., P. Erne, B. H. Ji, L. H. Block, W. Kiowski, and F. R. Buhler. 1984. Adrenaline induces vasoconstriction through post-junctional alpha- 2 adrenoceptors and this response is enhanced in patients with essential hypertension. J. Hypertension. 2(Suppl. 3):115-118.

29. Abboud, F. M., and J. W. Eckstein. 1965. Effects of norepinephrine and nerve stimulation on segmental vascular resistance in the perfused foreleg of the dog. Hypertension. XIII:49-71.

30. Green, H. D., and J. H. Kepchar. 1959. Control of peripheral resistance in major systemic vascular beds. Physiol. Rev. 39:617-686.

31. Ferreira, S. H., and J. R. Vane. 1967. Half-lives of peptides and amines in the circulation. Nature (Lond.). 215:1237-1240.

32. Brown, M. J., and I. Macquin. 1981. Is adrenaline the cause of essential hypertension? Lancet. i:1079-1082.

33. Tung, L. H., M. J. Rand, and H. Majewski. 1981. Adrenaline induced hypertension in rats. Clin. Sci. 61:191s-193s.

34. Zabludowski, J., S. Clark, S. G. Ball, A. J. Brown, G. C. Inglis, A. F. Lever, and G. Murray. 1984. Pressor effects of brief and prolonged infusions of epinephrine in the conscious rat. Am. J. Physiol. 246(Heart Circ. Physiol. 15):H683-H689.

35. Johnson, M. D., A. Grignolo, C. M. Kuhn, and S. M. Schanberg. 1983. Hypertension and cardiovascular hypertrophy during chronic catecholamine infusion in rats. Life Sci. 33:169-180.

36. Bravo, E. L., R. C. Tarazi, F. M. Fouad, D. G. Vidt, and R. W. Gifford. 1981. Clonidine-suppression test. A useful aid in the diagnosis of pheochromocytoma. N. Engl. J. Med. 305:623-626.

37. Goldstein, D. S. 1983. Plasma catecholamines and essential hypertension. An analytical review. Hypertension. 5:86-99.

38. Buhler, F. R., F. W. Amann, P. Bolli, L. Hulthen, W. Kiowski, R. Landmann, and E. Burgisser. 1982. Elevated adrenaline and increased $\alpha$-adrenoceptor-mediated vasoconstriction in essential hypertension. J. Cardiovasc. Pharmacol. 4:S134-S138.

39. Brodde, O.-E., A. Prywarra, A. Daul, M. Anlauf, and K. D. Bock. 1984. Correlation between lymphocyte $\beta 2$-adrenoceptor density and mean arterial blood pressure: elevated $\beta$-adrenoceptors in essential hypertension. J. Cardiovasc. Pharmacol. 6:678-682.

40. Tohmeh, J. F., and P. E. Cryer. 1980. Biphasic adrenergic modulation of $\beta$-adrenergic receptors in man. Agonist-induced early increment and late decrement in $\beta$-adrenergic receptor number. $J$. Clin. Invest. 65:836-840. 